\title{
O lado escuro do poder municipal: A mão de obra forçada e o Toque de Recolher no Rio de Janeiro Oitocentista*
}

\section{Amy Chazkel**}

Resumo: Durante mais da metade do século XIX, cobrindo boa parte do período imperial, as noites da cidade do Rio de Janeiro estiveram, quase sem interrupção, sob toque de recolher. Este artigo analisa a implementação dessa medida no contexto da história social e legal da cidade no período. Seu principal foco será o Edital de 1825, que estabeleceu o chamado "Toque de Aragão", a norma municipal batizada em homenagem ao Intendente de Polícia do Rio de Janeiro, responsável por ordenar a severa limitação da liberdade de circulação de pessoas durante a noite, bem como por impedir ou dificultar a reunião de determinados grupos de moradores daquela cidade, investigando suas causas e efeitos. A designação da noite como uma categoria jurídica e, com efeito, uma jurisdição à parte, estava relacionada ao controle dos trabalhadores e, em particular, à evolução do panorama do trabalho forçado na cidade mais populosa e politicamente significativa do Brasil recém-independente.

Palavras-chave: noite, toque de recolher, Rio de Janeiro

Abstract: The city of Rio de Janeiro was under curfew for a continuous period that lasted for more than half of the nineteenth century, for nearly the entire Empire. This article analyzes the implementation of a nighttime curfew in Rio in the context of the social and legal history of the decades to follow. The principal focus is the so-called Toque de Aragão-the edict named after its author, Fernando Teixeira de Aragão, the head of Rio's police-that imposed severe limitations on the nighttime freedom of movement and association for certain groups of persons, especially those of African descent. The designation of the nighttime as a legal category and, in effect, a separate jurisdiction, was related to the control of workers, and in particular to the changing landscape of forced labor in the most populous and politically significant city in newly independent Brazil.

Keywords: night, curfew, Rio de Janeiro

* Esta pesquisa foi realizada com o apoio financeiro da PSC-CUNY Research Foundation, do Queens College Dean of the Social Sciences Research Fund e do National Endowment for the Humanities. A autora agradeçe o auxílio de Mila Burns Nascimento, Henrique Espada Lima, Cristiana Schettini Pereira e Paulo Terra. Uma versão incipiente deste texto foi apresentada no Programa de Pós-Graduação em História/ Centro de Pesquisa em História Social da Cultura da Universidade Estadual de Campinas e aproveitou os comentários de Sidney Chalhoub e de os outros participantes do seminário.

** Department of History, City University of New York, Queens College and the Graduate Center. Contato: amy.chazkel@qc.cuny.edu 
Em 1936, Gilberto Freyre publicou um livro que traçava a "decadência do patriarcado rural", para citar o seu subtítulo, e o desenvolvimento do seu correlato urbano. Com o título de Sobrados e Mucambos, foi publicado três anos depois de Casa-Grande e Senzala e ganhou a forma de um ensaio histórico-sociológico que analisava de maneira criativa a geografia humana do campo e da cidade no Brasil. Utilizando-se principalmente de relatos de viagem estrangeiros, assim como evidências da arquitetura vernacular e da cultura material contemporâneas, Freyre narrava a ruptura da antiga ordem socioeconômica, quando a elite de fazendeiros passou a prestar menos atenção na Casa-Grande e mais nas mansões da cidade, no século XIX. De acordo com seu argumento, o crescimento das cidades havia modernizado - "re-europeizado" - as classes dos lavradores, enquanto eles se acostumavam com a vida pública. Assim, os até então separados domínios da casa e da rua começavam a entrelaçar-se; as famílias patriarcais da elite gradualmente permitiram que suas mulheres e crianças ultrapassassem a clausura da vida doméstica e passaram a conformar-se com o fim da escravidão.

O subtexto da análise, decididamente espacial, de Gilberto Freyre sobre a formação do "homem brasileiro" contém reflexões sobre um modo de interpretação histórica que ainda está por ser plenamente desenvolvido, algo que não foi feito por Freyre nem em seu amplo corpo de trabalho: o estudo de como a vida cotidiana foi contida por mudanças e limites não apenas espaciais, mas também temporais. A sociabilidade dentro de casa (em oposição a que se dá na rua), no que se refere à dinâmica do sobrado, não se configurava apenas pelo modo como os quartos eram distribuídos, mas também se desenhava pela maneira como eram iluminados. Freyre ainda descreve como a iluminação pública, anteriormente uma questão estritamente privada e encontrada exclusivamente nas casas dos mais abastados, passou a ocupar, também, as ruas. Com isso, os espaços urbanos comuns se tornaram verdadeiramente públicos, e chegaram "os primeiros brilhos de dignidade da rua, outrora tão subalterna que era preciso que a luz das casas particulares e dos nichos dos santos a iluminasse pela mão dos negros escravos ou pela piedade dos devotos". ${ }^{1}$ A diferença entre o que Freyre chama de "privatismo" e o espírito público (ou virtude pública) havia surgido por causa do fim das restrições habituais e legais à circulação durante a noite - e não apenas por causa da nova presença dos moradores nas ruas das cidades brasileiras.

A ascensão da cultura urbana poderia ocorrer apenas quando as ruas da cidade se tornassem um lugar hospitaleiro, um local de prestígio, segundo Freyre. Repleta de cadáveres de animais, frutas apodrecidas e de esgoto a céu aberto, a rua era, anteriormente, um lugar inacessível durante a noite. O "respeito" tinha, para a rua, uma dimensão especificamente temporal: ele descreve, por exemplo, as regras que proibiam os senhores de baterem publicamente nos escravos depois que os sinos da igreja soassem às 9 horas da noite. Implícita na análise espacial icônica de Freyre, em outras palavras, está a percepção de que a relação entre a jurisdição pública e a privada, entre o poder público e o privado - central tanto para a história urbana quanto para o estudo das sociedades escravocratas e da formação do Estado - se desenrolou não apenas no espaço, mas também no tempo.

O que aconteceria se tornássemos o tempo urbano, em vez do espaço urbano, o objeto de nossa análise? Histórias urbanas do Brasil têm habitado na diferença entre casa e rua, e as histórias mais recentes e críticas têm questionado e complicado essas distinções gritantes. Pesquisas fascinantes sobre a efervescência cultural

1 FREYRE, Gilberto. Sobrados e Mucambos: Decadência do Patriarchado Rural no Brasil. São Paulo: Companhia Editora Nacional, 1936, p. 18-19. 
nas regiões boêmias da cidade, os trabalhadores portuários radicalizados nos distritos marítimos, a vida social singular das famosas praias do Rio de Janeiro e os espaços de resistência e rebelião em praças públicas têm proporcionado uma rica análise da importância central de disputas pelo espaço urbano para a história social e política do Brasil, da América Latina, do Mundo Atlântico e, de fato, do chamado Sul Global. É claro, porém, que, assim como o espaço, o tempo também merece atenção analítica, visto que delimita dramaticamente a ação e o comportamento de um modo distinto das já amplamente estudadas disputas pelo território da cidade.

No Rio de Janeiro, no período tratado neste artigo, o tempo funcionava como um recurso renovável para aqueles que buscavam o abrigo da escuridão e do descanso de seu trabalho diário, e para as autoridades, em seus esforços para manter o controle sobre a população crescente e diversificada da cidade. A imposição de um toque de recolher durante certas horas e para determinadas pessoas condicionou o trabalho diário e as rotinas de lazer dos moradores da cidade que eram mais vulneráveis socioeconomicamente, lembrando-os diariamente de que alguns eram mais iguais do que outros.

Se ninguém seguiu a tentativa de Freyre de sistematicamente se debruçar sobre o ritmo diário da vida urbana e reconhecer a importância analítica da noite em oposição ao dia, o mesmo não ocorreu com a narrativa de modernização que também fundamenta amplamente o seu trabalho. Os poucos que trataram da iluminação gradual da cidade, que tornou possível a vida pública durante as 24 horas do dia, a associaram a um avanço tecnológico inevitável que formou um espaço urbano reconhecidamente moderno. ${ }^{2} \mathrm{~A}$ análise dos documentos administrativos relativos à iluminação pública no Rio de Janeiro do século XIX — produzidos pelas autoridades municipais parece corroborar com essa história familiar e previsível de modernização e progresso, de moradores que se aventuraram nas ruas, pouco a pouco, se unindo para formar um público moderno.

Os documentos da polícia, no entanto, proporcionam uma visão diferente. A cidade do Rio esteve sob o toque de recolher por um período ininterrupto que durou por mais da metade do século XIX, durante quase todo o Império. Este artigo analisa a implementação do toque de recolher, no contexto da história social e legal das décadas seguintes à implementação dessa medida. O principal foco é o Edital de 1825, que estabeleceu o chamado "Toque de Aragão" — a norma municipal no Rio batizada em homenagem ao Intendente de Polícia que ordenou a severa limitação da liberdade de circulação de pessoas durante a noite, e as reuniões de determinados grupos de cariocas - , investigando suas causas e efeitos.

Durante o dia, os visitantes estrangeiros no Rio, nas primeiras décadas do Império, se valiam de referências sonoras para evocar o clamor urbano, repleto de grupos de escravos e sua "tagarelice incessante", que eles muitas vezes contrastavam com o silêncio profundo após o dobrar dos sinos das igrejas, que sinalizava o início do toque de recolher. ${ }^{3}$ Um visitante inglês, escrevendo na década de 1830,

2 O trabalho clássico que trata da história social da iluminação urbana: SCHIVELBUSCH, Wolfgang. Disenchanted Night: The Industrialization of Light in the Nineteenth Century. trans. Angela Davies. Berkeley, CA: University of California Press, 1995. Outros exemplos são: BOONE, Christopher. The Rio de Janeiro Tramway, Light, and Power Company and the "Modernization" of Rio de Janeiro during the Old Republic. Toronto: Univ. of Toronto Press, 1995 e FERREIRA, Milton Martins. A evolução da iluminação na cidade do Rio de Janeiro. Rio de Janeiro: Synergia; Light, 2009.

3 WALSH, Robert. Notices of Brazil in 1828 and 1829, reproduzido em: CONRAD, Robert E. Children of God's Fire: A Documentary History of Black Slavery in Brazil. Princeton: Princeton University Press, 1984, 219; EBEL, Ernst. O Rio de Janeiro e seus arredores em 1824. São Paulo: Companhia Editora Nacional, 1972, p. 73. Ver em geral: LEITE, Miriam Lifchitz Moreira. Livros de viagem (1803-1900). Rio de Janeiro: Editora UFRJ, 1997. 
observou que os escravos corriam para evitar a violação do toque de recolher das 10 horas da noite, e "ai daquele que fosse flagrado" pela polícia na rua depois dessa hora. Ele escreve: "Nada poderia ser mais surpreendente para um estranho do norte... do que encontrar as ruas e os belos bairros da cidade praticamente desabitados e silenciosos como as ruínas de Tebas ou Palmyra". ${ }^{4}$ Tal impressão, no entanto, não corresponde plenamente à verdade.

Existem poucas - se é que existem - narrativas da vida pública cotidiana depois do escurecer. Apesar do senso comum sobre os espaços públicos "desertos" durante a noite na Corte Imperial, as ruas do Rio evidentemente não estavam vazias no período da escuridão. A história da vida cotidiana do Rio de Janeiro do século XIX termina no pôr do sol, mas a documentação a esse respeito, ao que parece, não. $O$ toque de recolher a que aquele viajante inglês se referia entrou em vigor logo após a Independência, junto com uma série de decretos policiais e regulamentos municipais que criminalizaram, para a maioria, o ato de estar em qualquer espaço público após o dobrar dos sinos das igrejas à noite. Na medida em que as interdições são um indício do que as pessoas realmente fazem, podemos supor que, no século XIX, o Rio estava vivo depois do escurecer. Os registros nos arquivos das prisões que tais interdições produziam são vislumbres inestimáveis de um pequeno e fundamental período na vida pública após o pôr do sol, em um momento anterior à era da famosa vida noturna do Rio de Janeiro - em outras palavras, em uma época em que muitos duvidavam da sua própria existência. Além disso, esses documentos são artefatos fascinantes do exercício diário do poder municipal na sua relação com os trabalhadores da cidade.

O controle do ritmo diário da vida é um exemplo do poder local por excelência; é uma questão cotidiana sem qualquer efeito direto sobre as leis e a jurisprudência em nível nacional. Aqueles que exerciam o poder municipal designavam jurisdições temporais e não apenas espaciais. A mudança legal que ocorria a cada noite, com o pôr do sol, se deu no contexto de contínuas lutas pelo poder entre a polícia, os indivíduos (especialmente os proprietários de escravos) e a Coroa. Prestar atenção ao tempo cotidiano pode proporcionar uma nova forma de examinar a questão crucial de quem - quais instituições ou indivíduos - deve decidir, estabelecer e fazer cumprir as normas de moralidade pública e do comportamento correto. ${ }^{5}$ As maneiras pelas quais as regras do período noturno foram impostas têm fortes implicações para a compreensão do poder municipal, não apenas como o equilíbrio, às vezes tenso, entre a Câmara Municipal e a polícia, mas, além disso, como o equilíbrio entre os poderes público e privado. ${ }^{6}$ Os escravos podiam ser açoitados e encarcerados no Depósito Geral se fossem flagrados nas ruas depois do anoitecer; senhores de escravos, no entanto, poderiam escrever um bilhete concedendo-lhes isenção de tal regulamento. O nexo das interdições legais e práticas de policiamento depois de escurecer criou uma jurisdição muito especial, que desaparecia ao nascer do sol, mas se renovava todas as noites. Parece claro que não apenas a escravidão ilegal, mas também a mudança legal ocorrida durante a noite, completa o quadro da paisagem sociolegal e explica a precariedade da liberdade para a maioria não branca da cidade.7 A designação da noite como

4 HOLLOWAY, Thomas. Policing Rio de Janeiro: Repression and Resistance in a Brazilian City. Stanford, CA: Stanford University Press, 1993, p. 22-23.

5 Ver: HARTOG, Hendrik. "Pigs and Positivism". Wisconsin Law Review. Madison, Wl. 901, 1985, p. 899-935.

6 ALGRANTI, Leila Mezan. O feitor ausente: estudos sobre a escravidão urbana no Rio de Janeiro: 1808-1822. Petrópolis: Vozes, 1988; SCHULTZ, Kirsten. "The Crisis of Empire and the Problem of Slavery: Portugal and Brazil, c. 1700- C. 1820”. Common Knowledge. Durham, NC: Duke University Press, 11:2, 2005, p. 275-77.

7 CHALHOUB, Sidney. A força da escravidão: llegaldade e costume no Brasil oitocentista. São Paulo: Companhia das Letras, 2012. 
uma categoria jurídica e, com efeito, uma jurisdição à parte, estava relacionada ao controle dos trabalhadores e, em particular, à evolução do panorama de trabalho compulsório na cidade mais populosa e politicamente significativa do Brasil recémindependente.

Uma regra aparentemente excêntrica e arcaica como a criminalização de estar nas ruas depois do anoitecer parece fazer tanto sentido quanto a sua eventual extinção, à medida que a cidade se modernizava e se livrava do duplo anacronismo da escravidão e da monarquia. Por causa das tensões sociais inerentes a uma cidade de trabalhadores escravizados, e da violência necessária para governá-la, o policiamento tirânico parece ser uma característica orgânica da paisagem urbana. A história geralmente contada sobre o policiamento da cidade enfoca estreitamente a questão da ordem e da desordem social urbana e o controle de escravos, e da mitigação de potenciais revoltas pela instituição policial, então em desenvolvimento. Este artigo se une a uma útil conversa iniciada pelos historiadores que começaram a investigar o que existe para além da importante, mas já familiar, história do controle social e do policiamento draconiano. Esses trabalhos recentes procuram não apenas identificar, mas perscrutar o poder oficial para entender seu funcionamento no nível municipal e obter uma visão mais concreta de como a lei age sobre a cultura e a sociedade. ${ }^{8}$ Da mesma maneira, o que emerge dos registros arquivísticos produzidos pelo Toque de Aragão é uma história de repressão, e os documentos mostram claramente a presunção racista de culpabilidade de qualquer pessoa afrodescendente. Mas essa história é mais do que apenas outro exemplo do Estado autoritário esmagando o povo, e a criminalização de estar na rua depois de anoitecer vai além da questão de desigualdade social. Em vez de ser uma relíquia do Antigo Regime, foi uma prática antiga, mas também uma novidade do século XIX, que virou lei na esteira de uma crise de mão de obra urbana.

O toque de recolher diferenciava abertamente as classes sociais e só era aplicado aos escravos, aos que pudessem ser confundidos com escravos, como as pessoas livres de ascendência africana e, algumas vezes, aos estrangeiros. Os mais abastados e de pele mais clara foram explicitamente isentos.

Todas as pessoas não escravas nascidas no Brasil, independente da sua condição jurídica ao nascer (livres ou não), de acordo com a primeira Constituição do Brasil independente (ratificada em 1824) eram cidadãos a quem a igualdade era garantida perante a lei. É interessante notar, contudo, que, embora todos fossem capazes de exercer muitos desses direitos políticos e civis livremente, independentemente da sua etnia, no tangente à liberdade de ir e vir e ao uso da cidade, houve uma divisão racial gritante. ${ }^{9} \mathrm{O}$ toque de recolher não apenas discriminava as pessoas de acordo com a cor da sua pele, mas também exigia que a polícia o fizesse. Depois de escurecer, o regime legal mudava sutil, mas significativamente; o Rio se tornou uma cidade de não cidadãos em estado de emergência sob o domínio da polícia. ${ }^{10}$

8 SOUZA, Juliana Teixeira. "A autoridade municipal na Corte Imperial: Enfrentamentos e negociações na regulação do comércio de gêneros (1840-1889)". PhD diss. Universidade Estadual de Campinas, 2007; ABREU, Martha. O Império do divino: Festas religiosas e cultura popular no Rio de Janeiro, 1830-1900. São Paulo: Editora Nova Fronteira, 1999, cap. 3.

9 Este é mostrado dramaticamente na historiografia atual sobre a prática da re-escravização ilegal no Brasil dos Oitocentos. Ver principalmente: CHALHOUB, Sidney. A força da escravidão: llegaldade e costume no Brasil oitocentista. Op. cit. A questão da liberdade de ir e vir e da associação nos espaços públicos da cidade lembra o conceito do "direitos públicos" desenvolvido na obra da Rebecca Scott; ver: SCOTT, Rebecca. "Public Rights, Social Equality, and the Conceptual Roots of the Plessy Challenge", Michigan Law Review. Ann Arbor. v. 106, p. 777-804, 2009; e SCOTT, Rebecca; HEBRARD. Jean M. Freedom Papers: An Atlantic Odyssey in the Age of Emancipation. Cambridge, MA: Harvard University Press, 2012.

10 Para uma comparação instrutiva, ver: SPIELER, Miranda Frances. Empire and Underworld: Captivity in French Guiana. Cambridge, MA: Harvard University Press, 2012, p. 8-16. 
Até mesmo os homens e mulheres cuja circulação noturna na cidade era limitada pelo toque de recolher, tomavam as ruas constantemente após o anoitecer. Durante todo esse período, temos os registros policiais de pessoas que foram presas depois de escurecer, "fora de horas", para usar a linguagem corriqueira dos policiais. É bastante claro que os regulamentos e editais destinados a reduzir a socialização pública e a circulação de pessoal depois de escurecer não conseguiu fazê-lo, ainda que essas leis certamente tenham tido outros efeitos. ${ }^{11}$

Curiosamente, o toque de recolher não parece ter gerado muita controvérsia. Ele foi discutido ocasionalmente e com naturalidade em jornais e, mais tarde, na literatura folclórica. Aparece em trabalhos de ficção ambientados no início do Império, servindo para destacar o quão diferente era a vida diária no passado. Juristas e ensaístas políticos do início e de meados do período imperial, que escreveram abundantemente sobre uma infinidade de outros assuntos — da punição corporal ao habeas corpus para o direito marítimo - não se preocuparam com o toque de recolher noturno. Essa marginalidade teórica em si é reveladora. A escassez de escrita jurídica, abordando diretamente o toque de recolher também significa que, para estudar a sua imposição e os seus efeitos, é preciso contar com os registros de prisões, e não muito mais que isso. Há certamente outras histórias a serem contadas sobre a vida depois do escurecer no Rio do século XIX, mas a história social e legal do toque de recolher fornece um começo promissor para a compreensão desse mundo ainda desconhecido. Os registros policiais indicam simultaneamente alguns dos tipos de trabalho e lazer noturnos em que cariocas do século XIX se envolviam e revelam a criação da noite como uma categoria sociojurídica. Com isso, podemos capturar o processo de um "sistema social e cultural se definindo". ${ }^{12}$

Este artigo deixa para futuros estudos a importante tarefa de reconstruir a história da sociabilidade pública e talvez, além de tudo, o trabalho que se fazia depois do pôr do sol a despeito da interdição criminal de estar na rua depois do toque de recolher. É impossível, porém, considerar estes aspetos da vida noturna da cidade — os batuques, os encontros religiosos e cívicos clandestinos, o povo que circulava indo e vindo das tavernas até de madrugada, e eventualmente (de meados do século em adiante) as sessões noturnas do teatro e os cafés-concertos, as regatas que saiam à meia-noite — sem parar primeiro para considerar o fato de que, durante todo este tempo, estar no espaço público depois de anoitecer era oficialmente um crime.

\section{O que a lei enxergava no escuro, $1825-1878$}

Formas pré-modernas de iluminação pública eram caras, fracas e dependiam completamente da iniciativa particular. Quando a sede do vice-reino do Brasil se mudou de Salvador para o Rio, em 1763, a iluminação pública não existia no país, em lugar nenhum. Os únicos vislumbres de luz após o pôr do sol vinham de lanternas penduradas na frente de edifícios religiosos, candelabros, lanternas a óleo de baleia ou velas de cera. Chamas em nichos e altares nas paredes de algumas esquinas ou em fachadas de edifícios deixavam que os devotos rezassem até que os vi-

11 Os exemplos são muitos; veja Arquivo Geral da Cidade do Rio de Janeiro (AGCRJ), códice 40.3.78, folha 2. (Ofício, 18 de junho de 1836); Arquivo Nacional (AN), Polícia da Côrte, Códice 327, v.1 and 2; AN, Polícia da Côrte, Códice 330, v.6 and 7. Incidentes de prisões por estar nas ruas após o horário também são citados em CHALHOUB, Sidney. A força da escravidão: Ilegaldade e costume no Brasil oitocentista. Op. cit., p. 432.

12 MUIR, Edward; RUGGIERO, Guido. History from Crime: Selections from Quaderni Storici. trans. Corrada Biazzo Curry, Margaret A. Galucci, Mary M. Galucci. Baltimore: Johns Hopkins University Press, 1994, p. 226. 
gias noturnos fizessem suas rondas. Os moradores da cidade fechavam-se dentro de casa. Ruas estreitas eram perigosamente escuras. Residentes que precisavam se mobilizar pela cidade de noite usavam o luar ou sua própria lanterna.

Como parte dos melhoramentos do final do século XVIII na capital do vice-reino, a iluminação pública foi introduzida; as primeiras cem lâmpadas de azeite de peixe foram colocadas nas ruas centrais às custas do Estado, e ficavam acesas quando a lua não estava cheia. No início da década de 1850, o município firmou um contrato com uma empresa particular para a instalação de lâmpadas iluminadas a gás, colocadas nas áreas centrais da cidade. ${ }^{33}$ Enquanto o Rio noturno se iluminava gradualmente, durante as primeiras décadas depois da Independência, a questão da iluminação pública surgia repetidamente na correspondência administrativa entre as forças policiais e o governo municipal como um assunto da maior gravidade para a segurança e a "tranquilidade" públicas, para citar a linguagem que frequentemente aparece nos documentos. ${ }^{14} \mathrm{O}$ número exato e a localização das lanternas, quem financiava e assumia a responsabilidade pela sua instalação, e a rapidez e eficiência dela eram temas debatidos, mas o desejo de iluminar as ruas da cidade parece ter gerado pouca controvérsia. Também parece claro que a iluminação pública havia se tornado, ao menos por volta de 1840, uma questão para a polícia. ${ }^{15}$

A noite é definida nos textos jurídicos como o período entre o pôr e o nascer do sol. O momento em que a noite oficialmente começa e exatamente o que o escuro devia significar variava muito na tradição jurídica ocidental, mas um regime diferente sempre começava depois da escuridão. As leis visigótica e ibérica medieval, fontes para a lei ibero-americana, determinavam uma diferença entre alguns crimes que se cometiam depois do pôr do sol, para os quais os acusados recebiam castigos mais severos do que os mesmos crimes cometidos durante o dia, chegando até mesmo a serem avaliados de acordo com uma jurisdição separada. ${ }^{16} \mathrm{Na}$ jurisprudência inglesa, que é frequentemente citada nos escritos jurídicos portugueses e brasileiros, a noite começa "depois do pôr do sol e cessa quando há luz do sol suficiente para discernir o semblante de um homem". ${ }^{17}$ As Ordenações Filipinas, (o código português do século XVI em efeito antes do Código Criminal de 1830) prestam muita atenção à noite; as Ordenações mandam tocar o sino de recolher - o que, é importante notar, refere-se não ao horário do dia, mas à necessidade de permanecer em casa - indicando o tempo em que devem tocar e precisamente a que horas. ${ }^{18}$

Formalmente, as forças policiais profissionalizadas não existiam, seja de dia ou de noite, até o século XIX, mas o patrulhamento noturno tem raízes profundas na história ibero-americana. Na Europa medieval, guardas, "notáveis armados", se mantinham atentos aos portões da cidade durante o dia. À noite, guardas desarmados faziam patrulha, atentos a incêndios, intrusos e outros perigos. Esse foi,

13 Centro Cultural da Light, “A iluminação no Rio de Janeiro," ms.

14 Ver: AGCRJ, códices 8.4.57, 8.4.58, e 47.3.30.

15 Ver, por exemplo: AGCRJ, códice 8.4.58, folha 49; AGCRJ, códice 8.4.58, folha 70; AGCRJ, códice 8.4.57, folha 3; AGCRJ, códice 8.4.57, folhas 27-29.

16 VERDON, Jean. Night in the Middle Ages. Trans. George Holoch. Notre Dame, Indiana: University of Notre Dame Press, 2002, p. 100.

17 HUNGRIA, Nelson. Comentários ao Código Penal. Rio de Janeiro: Editora Forense, 1982 (1950), pp. 203205; SHUMAKER, Walter A.; LONGDORF, George Foster. The Cyclopedic Law Dictionary, 3. ed. Chicago: Callaghan and Company, 1940, p. 753.

18 Ordenações e Leis do Reino de Portugal, Tomo 1, Título 65, par. 13 and 14. Ver também: BARRETO FILHO, João Paulo de Mello; LIMA, Hermeto. História da polícia do Rio de Janeiro: Aspectos da cidade e da vida carioca. Rio de Janeiro: Editora A Noite, 1939, p. 33, 36. 
por vezes, um projeto de trabalho compulsório para o qual os privilegiados podiam "comprar substitutos". As Ordenações Filipinas também estipulavam as regras para o recrutamento e para o controle das patrulhas noturnas, os chamados quadrilhas e quadrilheiros. Os homens estavam sujeitos ao recrutamento forçado para fazer parte da força de segurança pública em Lisboa e em outras grandes cidades, cuja principal vantagem para o recruta era o fato de ser permitido a ele estar fora de casa durante a noite, sem precisar se submeter a qualquer pergunta. ${ }^{19}$ No Rio de Janeiro, o primeiro policiamento noturno, que incluiu não apenas quadrilheiros, mas também capitães do mato, encarregados de capturar escravos fugidos nas áreas em torno das cidades, consistiu, na verdade, de caçadores de recompensas empregados por proprietários de escravos e pelo governo municipal durante a era colonial. ${ }^{20}$

No Rio do início do século XIX, as restrições ao ir e vir depois de escurecer vinham da tradição portuguesa, mas essa história é inseparável da prevalência de escravos, cuja população foi estimada em $46 \%$ dos moradores do Rio em $1821 .{ }^{21} \mathrm{~A}$ Constituição de 1824 estabeleceu a liberdade de associação e igualdade perante a lei, mas também manteve os direitos de propriedade dos senhores de escravos e não deu nem direitos, nem o status de "pessoa" legal para os escravos no território brasileiro. A constituição tampouco providenciou regras explícitas para lidar com escravos, e o Brasil nunca adotou um código específico para eles (um "Code Noir" como nos domínios coloniais franceses), levando a um equilíbrio frágil entre a jurisdição particular dos proprietários e a lei criminal para "controlar" os escravos. A polícia, a Câmara Municipal e os senhores de escravos trabalhavam juntos — embora frequentemente em desacordo - para controlar escravos nos espaços públicos do Rio. O toque de recolher em si não entrou no Código Criminal de 1830, que valeu durante todo o Império, mas a noite, sim. No Código Criminal, a noite é uma "circunstância agravante": entrar na casa alheia de noite levava a uma pena de prisão duas vezes maior do que de dia. ${ }^{22}$ Porém, a antiga distinção entre o dia e a noite apareceu no policiamento e na prática judicial pós-Independência como um destes meios de controle. Estar na rua depois do toque de recolher foi um dos crimes relativamente leves que preocupavam a polícia, mas não constavam no Código Criminal de 1830; essa infração caía em uma ampla categoria de atividades (como a jogatina e a capoeira) que foram deixadas aos cuidados de uma combinação de regulamentos locais por um lado, e uma tradição vaga que agia no interesse de "ordem e tranquilidade pública" por outro. ${ }^{23}$

A regulação do tempo diurno no início do período imperial, e em particular as horas de trabalho, precisa ser entendida em conexão com a relação particular entre a polícia, o governo da cidade, representado pela Câmara Municipal, e os indivíduos privados que exerciam sua autoridade sobre os escravizados. As primeiras leis referentes ao trabalho, e em particular as duas leis de contratos de "Locação de Serviços" de 1830 e 1837 não faziam referência alguma às horas de trabalho, deixando implicitamente a questão sobre quando e por quanto tempo o trabalho iria acontecer inteiramente nas mãos da relação privilegiada entre empregadores

19 Sobre o final do século XIX e o início do século XX, ver: BRETAS, Marcos Luiz. Guerra das ruas: Povo e polícia na cidade do Rio de Janeiro. Rio de Janeiro: Arquivo Nacional, n.17, cap. 3, 1997, p. 59.

20 BARRETO FILHO, João Paulo de Mello; LIMA, Hermeto. História da polícia do Rio de Janeiro: Aspectos da cidade e da vida carioca. Op. cit., p. 36.

21 KARASCH, Mary. Slave Life in Rio de Janeiro, 1808-1850. Princeton, NJ: Princeton University Press, 1987, p. 60.

22 Lei de 16 de dezembro de 1830. Código Criminal do Império do Brasil. cap. III, Secção 1, artigo 16; secção VI, artigo 211. Disponível em: http://www.planalto.gov.br/ccivil_03/leis/lim/lim-16-12-1830.htm

23 HOLLOWAY, Thomas. Policing Rio de Janeiro: Repression and Resistance in a Brazilian City. Op. cit., p. 61. 
e empregados. Na lei de 13 de setembro de 1830 ("Lei de Locação de Serviços”), que definia obrigações de serviço e punia trabalhadores que não as cumprissem, a definição das horas de trabalho estava incluída na categoria genérica de "todas as outras condições do contrato", a serem definidas fora do alcance do estado. ${ }^{24}$ As autoridades administrativas do Rio - e principalmente a Câmara Municipal também não deram muita atenção ao tempo do dia, tratando desse assunto apenas de modo periférico. O Código de Posturas Municipais, em 1838, não estipulava um toque de recolher e não continha mais do que regras esparsas e pouco estritas — além de frequentemente desrespeitadas - sobre as horas de funcionamento do comércio. ${ }^{25}$ Durante o mesmo período, entretanto, a Intendência de Polícia passou a responsabilizar-se por um leque amplo de responsabilidades administrativas, incluindo a supervisão de obras públicas, o controle sobre a pequena criminalidade e o policiamento dos escravos, entre outras tarefas do gênero. O desejo do Estado de tornar a cidade mais ordeira e adequada ao papel de sede do império português levou as autoridades a tentar impor um maior controle sobre a instituição que costumava manter-se sob a jurisdição privada. Isso levou os representantes do poder público a entrar em conflito com os proprietários de escravos. ${ }^{26} \mathrm{Assim}$, em suma, o tempo diário era uma frente importante na luta diária pelo controle social, mas foi basicamente deixado de fora das Posturas Municipais e dos regulamentos sobre o trabalho diurno. Assim, se havia algum tipo de regulação, esta era uma questão para a polícia, bem como para o sistema paternalista de controle social operado pelos proprietários de escravos.

Numa cidade atordoada pela última década e meia de mudanças políticas e demográficas da época da Independência, e sobretudo uma cidade onde mais ou menos a metade dos residentes eram propriedade da outra metade, não é nem um pouco surpreendente que o assunto de "tranquilidade pública" fosse constantemente levantado. Lendo a torrente diária de ofícios e outros documentos que fluíam da Intendência Geral da Polícia da Corte, fica clara a ampla variedade de temores que tal instituição policial, ainda em formação e em fluxo, enfrentava. Naturalmente, o medo da "desordem pública" foi dominado pelos escravos (mas não limitado a eles), que percorriam a cidade durante o trabalho cotidiano. Logo depois de assumir sua posição como o sexto Intendente de Polícia da Corte, o fidalgo lisboeta e jurista Francisco Alberto Teixeira de Aragão escreveu para os seus colegas na Corte Imperial e nas outras cidades sobre os perigos das "sociedades ilícitas", dos estrangeiros que existiam em abundância, andando pelas ruas sem documentação alguma, e das mais variadas ameaças à segurança geral. ${ }^{27}$ Aragão, como autoridade máxima da polícia, introduziu várias medidas que estabeleceram na Corte uma força policial centralizada e poderosa cujo funcionamento se dava vinte e quatro horas por dia. ${ }^{28}$

24 Coleção das Leis do Império do Brazil, 1830. Rio de Janeiro: Tipografia Nacional, 1876, p. 31.

25 Código de Posturas Municipais. Seção 1—saude pública; seção 2-polícia. Ver: ABREU, Martha. O Império do Divino, p. 193-97.

26 SCHULTZ, Kirsten. "The Crisis of Empire and the Problem of Slavery". Op. cit., p. 276-77.

27 Ver por exemplo AN, Seção de Guarda SDE 001, códice 325, v. 4; AN, GIFI, Caixa 6J 80.

$28 \mathrm{Em}$ um documento comprido reorganizando a força policial carioca (Intendência Geral da Polícia) e criando comissários e cabos para trabalharem sob o Intendente, em novembro de 1825, Aragão afirmou o policiamento profissional contínuo da cidade ao longo dos 24 horas do dia: "Toda a pessoa, seja de que condição for, poderá recorrer dos Comissários e Cabos da Polícia a qualquer hora do dia, ou da noite, para requerer a manutenção da sua probidade, segurança individual ou familiar e para reprimir todos aquelles factos que sendo legalmente prohibidos lhe podem ser prejudiciais por alguma maneira"; AN, Fundo: Polícia da Côrte, códice 332, folhas 2-3. 
Um dos primeiros problemas que Aragão enfrentou nos seus primeiros meses como Intendente da Polícia no Rio foi um debate furioso sobre o recrutamento forçado de escravos para trabalharem nas obras públicas e a necessidade desesperada de mais mão de obra para acompanhar a crescente necessidade de infraestrutura. Parece que os escravos, que de fato eram ganhadores fazendo o trabalho determinado por seus senhores, estavam sendo "apanhados" das praças públicas e colocados para fazer trabalho compulsório, construindo fortificações para a cidade. Senhores de escravos e, em alguns casos, oficiais da polícia, expressavam horror em relação às supostas violências contra o direito de propriedade, enquanto as autoridades municipais se preocupavam em terminar os muitos projetos de obras não completados pela cidade sem a disponibilidade da mão de obra necessária. Os requerimentos e as portarias sobre esse assunto saindo do gabinete do próprio Aragão eram cada vez mais conturbados nos meses finais de $1824 .{ }^{29}$

Imediatamente depois dessa controvérsia sobre como conseguir trabalhadores para as obras públicas sem ameaçar a ordem escravista, em um dos seus primeiros atos como intendente, Aragão emitiu novos regulamentos policiais num edital datado de janeiro de 1825 . Esse edital determinava que qualquer pessoa, fosse escravo ou livre, que fosse parada "por qualquer ronda", teria que ser submetida à interrogação. Resistir era automaticamente considerado um ato criminoso ("importa uma resistência"), e "será até empregada a força, ser for necessário, àquele que se insurgir". A provisão central no edital de 1825 estabeleceu o que logo passaria a ser conhecido como o "toque de Aragão": pela lei às 10 horas no verão e às 9 horas no inverno começava a hora de se recolher dentro de casa; rondas tinham o direito absoluto de fazer revistas a qualquer pessoa que estivesse na rua depois do famoso "Toque de Aragão", para verificar se a pessoa carregava qualquer instrumento que pudesse ser usado em um crime. Os sinos da igreja de São Francisco de Paula e do convento de São Bento tocavam por meia hora para anunciar o momento de recolha a todos e excluir a possibilidade que alguém pudesse alegar que não soubesse da hora. ${ }^{30}$

Ironicamente, era exatamente quando não se podia mais enxergar o rosto de uma pessoa - parafraseando a definição legal da noite - que os policiais ganhavam poderes fortalecidos (e principalmente extralegais) para prender pessoas. O "Toque de Aragão" fazia parte de uma tendência de policiamento no Rio durante o primeiro século pós-Independência, um padrão emergente que dava cada vez mais autoridade aos policiais quando tratavam dos crimes e contravenções mais comuns, como a vadiagem e o sair "fora de horas", efetivamente dando aos representantes da Justiça nas ruas o papel de policial, juiz e júri, de uma só vez. A regra para a aplicação dessa nova lei exigia que não se abusassem dela, nem a aplicassem a "pessoas notoriamente conhecidas e de probidade"; a lei era feita explicitamente para ser aplicada seletivamente, de acordo com a classe social e as

29 AN, Polícia da Côrte, Códice 323, v. 8; AN, Polícia da Côrte, Códice 327, v.1 e 2. Os esforços constantes para obter mão de obra forçada para as obras públicas na Corte Imperial, além da historiografia volumosa sobre os africanos livres, são bastante documentados. Além dos outros documentos aqui citados, ver: AGCRJ, códice 6.1.25, folha 14.

30 BARRETO FILHO, João Paulo de Mello; LIMA, Hermeto. História da polícia do Rio de Janeiro: Aspectos da cidade e da vida carioca. Op. cit., p. 288-89. José Vieira Fazenda consta que o convento de Santa Teresa também tocava um aviso cada noite 20 minutos antes do sino de recolher, como um gesto de "piedade" para os escravos, que não teriam tempo de ir correndo para casa e evitar o castigo que recebiam por estarem nas ruas "fora de horas"; citado em: Idem, Ibidem, p. 289. Ver também: HOLLOWAY, Thomas. Policing Rio de Janeiro: Repression and Resistance in a Brazilian City. Op. cit., p. 46-47; BRANCO, Zoraia Saint'Claire. "Estórias da Polícia do Rio de Janeiro". Cadernos de Segurança Pública. Rio de Janeiro. 1:0, 2009, p. 3. 
desigualdades raciais da época. ${ }^{31}$ José Vieira Fazenda, no seu conto nostálgico do Toque de Aragão, lembra que "era o sinal de correr ou de recolher, e o negrinho que andasse na rua desta hora em diante, sem bilhete de seu senhor, ser engalfinhado no xadrez ou no calabouço e chegavam-lhe a roupa ao pelo". ${ }^{32}$

A ordem de Aragão mostrava como a noite podia fazer ruir a diferença entre escravo e livre. Dependendo das circunstâncias, entretanto, o novo regime jurídico que começava com o pôr do sol também podia alargar essa diferença. Depois do sino de recolher, tornava-se ilegal assobiar nas ruas ou fazer qualquer coisa que pudesse ser encarada como um sinal. Essa proibição aplicava-se "aos negros e gente de cor a qualquer hora depois de escuro, mesmo que fosse antes do sino de recolher." Um escravo nas ruas fora de horas "em qualquer loja, taverna, botequim ou casa de tavolagem" podia ser mandado para o Calabouço e estar sujeito a açoites; pessoas não escravas eram obrigadas a pagar uma multa. $33 \mathrm{O}$ edital também tinha como alvo pequenos negócios nos quais as pessoas se reuniam depois do horário de trabalho, sugerindo que o tipo de pessoa que estaria sujeito a tal toque de recolher, de fato, era cliente de lugares como tabernas no Rio do início do século XIX, apesar da escuridão extrema e de ruas supostamente inóspitas. De acordo com o historiador Thomas Holloway, em sua obra clássica sobre a polícia do Rio de Janeiro,

as instruções de Aragão, centrando-se no toque de recolher e nos locais de entretenimento público e interação social tanto para os escravos quanto para os não-escravos de classes mais baixas, colocavam as disposições de direitos civis da constituição em um contexto mais realista. "A lei será a mesma para todos" acabou por ser uma declaração entusiasmada desde o princípio, tendo pouco a ver com a vida nas ruas.

Em parte, o tratamento desigual de pessoas diferentes depois de escurecer deriva do fato de que os escravos não tinham personalidade jurídica, mas eram propriedade de alguém, e a sua fuga foi uma das preocupações centrais da polícia do Rio de Janeiro. Os negros livres, no entanto, encontravam o mesmo problema que os escravos, assim como os pobres em geral. Para citar Holloway novamente: “... as pessoas de 'integridade' foram poupadas das restrições do toque de recoIher" e da indignidade das revistas corporais". ${ }^{34}$ O regulamento levou à suposição patentemente falsa de que a polícia poderia reconhecer visualmente quem era escravo e quem não era.

Quando o "Toque de Aragão" foi implementado, esse regulamento ostensivamente deixava as atividades normais ocorrerem do jeito como sempre ocorriam; ainda que fosse contra a lei estar nas ruas à noite, o comércio diurno andava como era preciso nessa cidade portuária em expansão. Além de limitar os movimentos de algumas pessoas depois de escuro, o Toque de Aragão literalmente transformava a vida material. Como Sandra Lauderdale Graham explica, depois de anoitecer

os escravos carregavam cartas escritas pelos senhores para explicar sua presença na rua e os cortiços trancavam os seus portões contra escravos fugidos e desordeiros, mantendo os seus residentes no lado

31 HOLLOWAY, Thomas. Policing Rio de Janeiro: Repression and Resistance in a Brazilian City. Op. cit., p. 46.

32 Citado em BARRETO FILHO, João Paulo de Mello; LIMA, Hermeto. História da polícia do Rio de Janeiro: Aspectos da cidade e da vida carioca. Op. cit., p. 289.

33 HOLLOWAY, Thomas. Policing Rio de Janeiro: Repression and Resistance in a Brazilian City. Op. cit., pp. 4647. Sobre a dificuldade em determinar quem era escravo e as mudanças na prática jurídica de quem teve o ônus da prova nesse respeito, ver: CHALHOUB, Sidney. A força da escravidão: Ilegaldade e costume no Brasil oitocentista. Op. cit., cáp. 9.

34 HOLLOWAY, Thomas. Policing Rio de Janeiro: Repression and Resistance in a Brazilian City. Op. cit., p. 47-48. 
de dentro. As ferramentas que um artesão carregava diariamente sem problema nenhum, durante as horas úteis do dia, viravam armas depois do sino vespertino da "Ave Maria" e eram proibidas. ${ }^{35}$

O fato de ela mencionar as horas úteis aqui é significativo: o Toque de Aragão dizia respeito à imposição de restrições a certas liberdades sem prejudicar a economia urbana. Não era somente um medo da "rua" que inspirava essas restrições, como sugere Lauderdale Graham; foi a maneira com que os oficiais administravam a diferença entre o dia e a noite, considerando o seu medo do caos potencial na vida pública urbana e não perdendo de vista, também, o jogo de interesses econômicos. O trabalho diurno e o recolhimento noturno funcionavam juntos.

\section{Fora de horas}

Em abril de 1829, o Intendente Geral da Polícia da Corte mandou uma carta ao Inspetor do Arsenal da Marinha. Essa carta avisava que haviam sido presos oito homens, todos marinheiros, que "andavam fazendo desordens" e, além do mais, estavam "fora de horas". Em nome do interesse da "tranquilidade pública" e do bom policiamento, foram todos mandados para o trabalho que o inspetor achava conveniente. ${ }^{36}$ Quatro anos mais tarde, em 1833, e também na cidade do Rio, o Juiz do Crime do Bairro de São José relatou à Inspetoria Geral da Polícia que "o preto João Braga, que diz ser forro e espanhol", foi preso "por ser encontrado a uma hora da noite por um pedestre". ${ }^{37}$

Nesses dois casos, e em outros tantos semelhantes encontrados nos arquivos da polícia e Justiça do início do Império, os policiais do Rio nos anos de 1820 , 30, e 40 varriam pessoas das ruas da Corte Imperial e as mandavam à cadeia, sujeitavam-nas a açoites (no caso dos escravos) e, além de tudo, as enviavam ao trabaIho compulsório nas várias obras públicas na Corte, para a construção de estradas, a limpeza das praças, a construção e o conserto das fortificações da cidade. O crime pelo qual essas pessoas foram presas era antigo, mas estava aparecendo nas ocorrências policiais das décadas de 1820, 30, e 40 em um contexto e uma forma muito novos: "andar na rua fora de horas", na linguagem da época.

O famoso Toque de Aragão iniciou um período contínuo de cinquenta e três anos durante os quais o anoitecer ativava um estado de exceção no funcionamento normal da Justiça, o que em princípio previa um estado de direito, apesar da identificação persistente entre as funções de polícia e Justiça. Outros regulamentos subsequentes alteraram ou refinaram o edital de 1825. Em 1831, o toque de recolher foi renovado por causa do que se considerou ser uma onda de crimes. $A$ partir de então, ele começaria ao pôr do sol (por volta de 18h30), em vez das 9 ou 10 horas, e se aplicava somente aos escravos e marinheiros. Naquele ano, das 224 pessoas presas entre o final de maio e o início de junho, 34 o foram por estar fora de horas (14 marinheiros e 20 escravos), 35 por vadiagem e 25 por estarem com armas ilegais, as duas outras categorias mais comuns. Apesar do nervosismo da polícia na década de 1830, muitos eventos noturnos nos espaços públicos do Rio eram povoados por escravos, pessoas livres de cor, e outros que seriam sujeitos

35 LAUDERDALE GRAHAM, Sandra. "Making the Private Public: A Brazilian Perspective”. Journal of Women's History. Baltimore, MD: Johns Hopkins University Press, 15:1, 2003, p. 28-42.

36 AN. Fundo: Polícia da Côrte, Códice 330, v. 6.

37 AN. Fundo: Polícia da Côrte, Códice 330, v. 7. Essa história é mais complexa ainda; ele foi encontrado com três chapéus e algumas roupas, dizendo que pertencia ao seu senhor, mas a polícia disse descobrir que foram roubadas. A resolução do caso não aparece nesse códice. 
ao toque de recolher. Se esses eventos atraíam um grande número de pessoas ou se a polícia achava que os participantes estavam em desordem, ou quando ocorriam depois do toque de recolher, os soldados da polícia dispersavam o grupo, e de acordo com o edital de 1825, prendiam qualquer pessoa que resistisse. Novas regras policiais, que foram emitidas em 1858 e buscavam profissionalizar e trazer mais eficiência à força policial, reforçaram a exigência de fechar toda taberna e botequim às 10 horas da noite, e reafirmaram que qualquer pessoa que fosse encontrada na rua "fora de horas" seria presumida criminosa. ${ }^{38}$

A polícia prendia mais escravos que pessoas livres por estar fora de horas, mas os dois grupos eram sujeitos ao regulamento, que deu muita margem à polícia para rondar à noite e administrar a Justiça nas ruas, prendendo pessoas que violavam uma lei que não existia no Código Criminal e que discriminava entre sujeitos que tinham garantia de igualdade perante a lei. Na pesquisa minuciosa de Thomas Holloway, usando o arquivo da polícia da Corte (a única pessoa que já estudou esse fenômeno do toque de recolher, que ele trata em algumas páginas de seu livro clássico sobre a polícia do Rio), ele descobriu que nenhuma pessoa considerada portuguesa foi presa por andar "fora de hora". Ele mostra ainda que "o toque de recolher se aplicava rotineiramente e quase exclusivamente às pessoas negras e pardas". 39 Holloway descobriu nos livros de matrícula do Calabouço, em 1857-58, que 25 dos 288 escravos recolhidos lá por ordem judicial eram presos por estarem "fora de horas"..$^{40}$ Nos anos de 1862 e 1865, andar na rua depois do toque de recoIher foi o motivo mais comum para ser preso, seguido pela vadiagem. Em ambos os anos, os presos por estar "fora de horas" compuseram um quarto do total de pessoas presas. ${ }^{41}$

Prisões por violações do toque de recolher e por outras infrações que se tornavam mais graves por acontecerem à noite aparecem espalhadas aleatoriamente em toda a documentação da polícia durante o período em que o toque de recolher vigorou. Embora esses casos sejam muito esparsos para permitir uma generalização sobre as circunstâncias em que a polícia tendia a efetuar as prisões, eles fornecem evidências do que estava em jogo para a polícia, ao parar e deter indivíduos encontrados nas ruas depois do anoitecer, e oferecem algumas dicas sobre a dinâmica de poder que governava o mundo noturno do Rio de Janeiro.

A ordem jurídica que entrava em vigor a cada noite depois do pôr do sol deve ser entendida no contexto da relação melindrosa entre os poderes público e privado que caracterizava esta época. De certo modo, a maneira como a polícia seletivamente aplicava o toque de recolher reafirmava a jurisdição privada dos senhores sobre seus bens humanos, tendendo, por exemplo, a conceder exceções para indivíduos escravizados, normalmente trancados dentro de casa depois do anoitecer, para atravessarem as ruas com a permissão de seus donos. Donos de escravos parecem ter frequentemente ignorado o toque de recolher, enviando trabalhadores escravizados às ruas à noite, certas vezes, ao que parece, intencionalmente em busca da proteção da escuridão. Em várias ocasiões, nos registros municipais de 1842, por exemplo, os escravos foram detidos e os seus senhores multados por despejo ilegal de lixo nas ruas ("deitar um pouco de sisco à praia”),

38 HOLLOWAY, Thomas. Policing Rio de Janeiro: Repression and Resistance in a Brazilian City. Op. cit., p. 79, 161, 191. 39 HOLLOWAY, Thomas. Policing Rio de Janeiro: Repression and Resistance in a Brazilian City. Op. cit., p. 198 40 Idem, Ibidem. "O Calabouço e o Aljube do Rio de Janeiro no século XIX”. In: MAIA, Clarissa Nunes; NETO, Flávio de Sá; COSTA, Marcos; BRETAS, Marcos Luiz. História das prisões no Brasil. Rio de Janeiro: Rocco, 2009, v. 1, p. $260-61$. 41 HOLLOWAY, Thomas. Policing Rio de Janeiro: Repression and Resistance in a Brazilian City. Op. cit., p. 201. 
após os sinos noturnos da igreja. ${ }^{42} \mathrm{~A}$ aplicação extraordinariamente seletiva do toque de recolher parece ter permitido alguma negociação; aqueles cujos escravos foram presos por estarem fora após horas, vez por outra contestavam a multa, não negando que haviam violado o toque de recolher, mas simplesmente implorando por clemência. Nesse mesmo ano de 1842, uma mulher escrava chamada Ermelinda foi presa por estar na rua depois do horário e, tornando a situação ainda pior, jogando na rua água suja que havia sido usada para lavar os pés. Dona Maria Ignacia de Negreiros Macedo, sua proprietária, enviou uma carta à Câmara Municipal implorando que Ermelinda fosse liberada do Depósito Público, "a ser a Supplicante pobre... e carregada de filhos, tendo seu marido fora em Serviços Públicos, hajão [por] bem aliviá-la da multa, que sem fundada Justiça Ihe querem fazer sofrer os dos guardas...".43

O período noturno ressaltava o poder que os senhores tinham de regulamentar o trabalho dos escravizados e de controlar os seus movimentos pela cidade depois do anoitecer, mesmo a despeito de leis rigorosas destinadas a impedir tal movimento. Ao mesmo tempo, porém, o toque de recolher deu ao governo municipal, em seu papel como o protetor do bem público, um poder adicional às custas dos senhores de escravos. O período noturno como uma categoria sociolegal se tornou uma parte crucial do desenvolvimento da relação entre o poder público e a alocação e o tratamento de trabalhadores - não apenas os trabalhadores escravizados, mas todos os socioeconomicamente vulneráveis e, especialmente, aqueles que pudessem ser confundidos com os escravos por causa de sua etnia aparente.

Nos anos de 1820 e 1830, a cidade do Rio passou por mudanças dramáticas que geraram um impacto sobre a questão de como o trabalho seria distribuído e em benefício de quem. Ondas de imigrantes, estrangeiros, exilados e imigrantes europeus e, especialmente, escravos africanos inundaram a cidade. Tanto a preocupação com a segurança em meio a uma série de revoltas (nos anos de 1830 para os de 1840) quanto as reivindicações por obras públicas que elevariam o perfil da nova capital do Império criaram uma premente necessidade por tais projetos civis, como a construção de fortificações e estradas. A chegada da Corte portuguesa em 1808, a abertura dos portos e o aumento vertiginoso da população do Rio de Janeiro criaram novas demandas de serviço e muitos dos exilados portugueses recém-chegados, incluindo os membros da Corte real, "adotaram a prática de comprar escravos com o objetivo de alugá-los como trabalhadores em obras públicas". ${ }^{44}$ Pessoas livres já estavam submetidas ao recrutamento militar forçado, com poucas proteções legais contra as ações arbitrárias de recrutadores e até mesmo de autoridades que o usavam como uma ferramenta para vinganças pessoais. ${ }^{45}$ É importante lembrar que os que estavam sujeitos a prisões por violações do toque de recolher e, em seguida, eram usados em trabalhos involuntários não eram apenas escravos, mas entre os presos e forçados a trabalhar em obras públicas estavam aqueles que caíam nas outras categorias que estavam sujeitas a esse dispositivo. Com o toque de recolher e a prática frequente de mandar as pessoas presas no arrastão noturno ao trabalho forçado, o governo municipal utilizou o regulamento contra o ato de estar nas ruas depois de escurecer para exercer o poder de atribuição do trabalho, assim como para trazer escravos, que eram anteriormente utilizados no trabalho doméstico, para os serviços nas ruas, reparando

42 AGCRJ, códice, 6.1.45, folhas 2 e 5.

43 Ela foi solta do Depósito cinco semanas depois, a multa paga; AGCRJ, códice, 6.1.45, folha 14.

44 SCHULTZ, Kirsten. "The Crisis of Empire and the Problem of Slavery”. Op. cit., p. 274.

45 LOVEMAN, Mara. "Blinded Like a State: The Revolt against Civil Registration in Nineteenth-Century Brazil". Comparative Studies in Society and History, Cambridge, UK: Cambridge University Press, 49:1, 2007, p. 27. 
estradas e realizando obras de construção. Tais serviços funcionavam como um sistema de cobrança compulsória de tributo, no qual o Estado no nível mais local assumiu o papel de redistribuir a mão de obra. Restrições à liberdade de ir e vir à noite, portanto, estavam diretamente relacionadas com a redefinição daquilo quer era considerado público.

A transição para um novo significado do "público" no final do período colonial e no decorrer do século XIX tem sido objeto de muitas pesquisas e estudos. A imposição do toque de recolher mostra que a nova abordagem do início do Império para a vida pública se relacionava ao trabalho urbano, não apenas como uma mudança do paternalismo para o laissez-faire do liberalismo, como é classicamente entendido, mas também como uma nova relação entre o Estado e os seus cidadãos, envolvendo o poder do Estado para extrair tributo. ${ }^{46}$

O fluxo de correspondências administrativas entre o gabinete do presidente da Província e o Comando do Corpo Policial da Província do Rio de Janeiro mostra a interessante ambiguidade a respeito da responsabilidade pelo toque de recolher durante o período em que sua vigência chegava ao fim, em 1870-1871. Em agosto de 1870 , um ofício vindo do Palácio do Governo da Província do Rio de Janeiro procurou "um agente de sua confiança" para "fazer o toque de recolher às 10 horas da noite... mediante uma gratificação conveniente...". Nem os soldados do corpo da polícia, nem o sacristão da igreja "Matriz d'esta Capital" queriam se "prestar a esse penoso serviço". Como sua necessidade parecia menos evidente para as autoridades, ninguém quis assumir o dever de fiscalizar o toque dos sinos da igreja. Essa conversa burocrática mundana, mas reveladora, não mostra apenas a importância minguante do toque de recolher, mas também deixa claras as questões interessantes sobre quem deveria assumir a responsabilidade de administrar a diferença entre o dia e a noite. ${ }^{47}$

Nos anos de 1870, o toque de recolher parece ter se tornado menos eficaz. Nunca fica muito claro o que uma queda no número de prisões realmente significa, mas nesse caso parece provável que a diminuição relativa a prisões por violações do toque de recolher indique uma falta de empenho na aplicação do bloqueio à noite, em vez de uma diminuição da atividade noturna. O toque de recolher estrito, ao que parece, começou a enfraquecer. Em julho de 1873, o comandante da Polícia Militar emitiu um lembrete de que todas as empresas deveriam fechar às 10 horas. Quando essa ordem foi defrontada com um clamor público, ela foi relaxada um pouco: às 10 horas como horário de fechamento ainda se aplicavam a "tabernas, casas onde bebidas alcoólicas ou cerveja eram vendidas, tascas e estabelecimentos similares que podem servir como pontos de encontro de bêbados, vagabundos e desordeiros". Mas os novos quiosques da cidade, em estilo europeu, assim como as confeitarias e os hotéis, foram dispensados e podiam ficar abertos até 1 hora da madrugada. A diferença, é claro, era de classe; à medida que a vida pública tornou-se mais comercializada, o toque de recolher aumentou a diferença de aplicação da lei, para ricos e pobres. Notadamente, se os estabelecimentos comerciais estavam agora isentos do toque de recolher às 10 horas da noite, logo seus clientes também o estavam. Durante essas três horas, das 10 horas da noite a 1 hora de madrugada,

46 GRAHAM, Richard. Feeding the City: From Street Market to Liberal Reform in Salvador, Brazil. 1780-1860. Austin, TX: University of Texas Press, 2010; VELLASCO, Ivan de Andrade. "Clientelismo, ordem privada e Estado no Brasil oitocentista: notas para um debate". In: CARVALHO, José Murilo de; NEVES, Lúcia Maria Bastos Pereira das (orgs.) Repensando o Brasil dos oitocentos: Cidadania, política, e liberdade. Rio de Janeiro: Civilização Brasileira, 2009, p. 73-100.

47 AN, PP, notação 0529; AN, PP, notação 0513. 
estava inteiramente a critério das patrulhas policiais prender alguém por violar o toque de recolher tecnicamente ainda em vigor. ${ }^{48} \mathrm{Em} \mathrm{1878}$, a Câmara Municipal aprovou uma lei deixando todos os negócios legítimos ficarem abertos até 1 hora de madrugada. Enfim, o Toque de Aragão foi formalmente revogado alguns meses depois, ainda em 1878.49

Vale notar que justamente quando o toque de recolher finalmente foi revogado depois daquelas muitas décadas, a cidade do Rio de Janeiro começou a contratar uma força policial particular para vigiar as ruas de noite. A Guarda Noturna rondava depois do escuro e continuava a tradição do Império do policiamento arbitrário. Agora sem o toque de recolher, o governo municipal controlava o comércio por meio da cessão de licenças; pequenos comerciantes que não conseguiam tirar uma licença tinham que fechar — o que muitos faziam — ou eram forçados a funcionar clandestinamente (às vezes pagando à polícia), — o que muitos outros também faziam. ${ }^{50}$

\section{A era da luz elétrica, a vida noturna carioca e o estado de exceção: um epílogo}

A iluminação pública se expandiu dramaticamente no final do século XIX; as lanternas de gás alcançaram a periferia suburbana, ainda iluminada a azeite de peixe, em 1877. Uma lei de 1879 deu início ao processo de trazer uma nova invenção, a luz elétrica, ao Rio. Em 1933, as últimas lanternas de gás que sobraram nos subúrbios foram substituídas por lâmpadas elétricas, assim terminando a carreira de quase oitenta anos do acendedor de lâmpada, um tipo popular da rua às vezes chamado de "profeta" por causa da vara que ele costumava usar para alcançar as lanternas altas. ${ }^{51} \mathrm{~A}$ iconografia popular, assim como a propaganda da empresa Light do início da época da luz elétrica, dava muita atenção ao desaparecimento dessa figura do século passado, o acendedor, que apareceu retratado como um escravo descalço e bagunçado, um trabalhador noturno que era o símbolo de atraso vergonhoso. No lugar do acendedor de lâmpada escravizado, foi colocado o técnico elétrico profissional, retratado como uma figura decididamente branca, um homem sorridente cumprindo seu devido trabalho de manutenção durante o horário útil do dia. ${ }^{22}$

Os cariocas já começavam a ocupar as ruas para diversão e sociabilidade à noite até bem antes da revogação, em 1878 , do regulamento que havia começado com o edital de Aragão em 1825. O entretenimento comercial noturno tinha brotado numa escala pequena nos anos de 1860 e as elites começaram a colonizar as ruas iluminadas a gás. A existência de uma vida noturna comercializada incipiente nos meados do século é evidenciada pelo pedido ocasional que a Câmara Municipal permitisse que negócios de entretenimento ficassem abertos mais tarde, citando tanto o costume quanto a demanda popular. O dono de um "Caffé Cantante" no Campo de Santana insistiu, numa carta escrita à Câmara em 1858, que "sendo-

48 HOLLOWAY, Thomas. Policing Rio de Janeiro: Repression and Resistance in a Brazilian City. Op. cit., pp. $257-258$.

49 Idem, Ibidem, p. 257-58. Logo depois do fim do toque de recolher, porém, o governo declarou um estado de sítio e reativou durante a Revolta do Vintem em 1880.

50 AN. Gifi 8N 014; BRETAS, Marcos Luiz. Guerra das ruas: Povo e polícia na cidade do Rio de Janeiro. Op. cit., p. $54,59,60,84$.

51 Centro Cultural da Light, "A iluminação no Rio de Janeiro," unpubl. ms.

52 Light, ano 2, v.2, número XIV (março de 1929), capa. 
-lhe apenas permitido ter este divertimento até às 10 horas da noite, recebe inúmeras reclamações" da clientela que queria "gastar mais tempo, visto como é curta a hora determinada". Ele queria oferecer "ao respeitável público, mas exigindo os distintos e qualificados espectadores que o frequentam, que por mais tempo deve aquele divertimento, pelo menos até às 11 horas, visto como é curto o espaço que esse preenche". ${ }^{33}$ O deferimento desse tipo de requisição ficou cada vez mais comum no final da década de 1850 e ao longo da década de 1860. A partir da década de 1880, lâmpadas funcionavam extensamente na zona urbana do Rio, o toque de recolher não existia mais e o povo podia sair mais facilmente depois de escuro. ${ }^{54}$

Contudo, vale dizer que a história do estado de exceção noturno não parece estar vinculada, pelo menos de um jeito simples e direto, às mudanças tecnológicas. Não foi a introdução gradual da luz artificial que mitigou a imposição do toque de recolher e os estados de sítio que foram impostos mais tarde. A história mais óbvia, que fala do progresso tecnológico, de fato também aparece aqui: vemos a crescente capacidade de iluminar os espaços públicos da cidade - em termos de financiamento público e também em termos da capacidade de produzir uma luz cada vez mais forte, barata e menos fedorenta. Mas o aparato jurídico que se desenvolvia para definir a noite como perigosa não se sincronizava com o ritmo de mudanças tecnológicas. Em vez disso, o governo municipal impunha essas leis nos momentos de conflito político ou da percepção de caos social. Regulamentos interditando que os cidadãos andassem na rua depois de uma dita hora passado do pôr do sol pretendiam limitar ao máximo a liberdade de movimento sem interferir no funcionamento normal das cidades: ou seja, deixando a distribuição das mercadorias para exportação das regiões agrícolas para a zona portuária da cidade e aprovisionando os trabalhadores que faziam essas indústrias funcionarem. Um centro comercial muito ativo como o Rio, que dependia de mão de obra cativa, cumpria o seu propósito econômico assim: a liberdade de movimento de dia, o recolhimento total de noite.

Embora não possamos reduzir a motivação por essa lei à necessidade de mão de obra cativa, o Toque de Aragão também não pode ser entendido separadamente desse fenômeno. A medida oficial que o impôs e as leis semelhantes que se seguiram faziam muito sentido no contexto do conflito que desabrochou nos meses anteriores à imposição do famoso edital: o conflito sobre o recrutamento de escravos (alheios) para trabalharem nas obras públicas que o governo local desenvolveu para responder à necessidade desesperada por mão de obra gerada por um sistema tributário. O edital de 1825 pode ser visto à luz da lei de novembro de 1831, que criou a categoria de "africanos livres", pessoas aprendidas do tráfico negreiro ilícito que logo acabaram providenciando a mão de obra forçada para a cidade (bem como para pessoas particulares), em resposta à preocupação constante da liderança municipal: quem iria providenciar o trabalho individual necessário pelo bem público - não em casas particulares, mas nos espaços compartilhados da cidade? O edital surgiu para resolver um problema específico e agudo: uma crise de abastecimento de mão de obra, o que logo foi combinado com o horror a qualquer tipo de "aglomeração" de gente avulsa e o medo da rebelião depois dos tumultos que aconteceram nas cidades do Norte e do Nordeste do país na década de 1830. Essas regulações que restringiam o movimento noturno para algumas classes de cariocas foram impostas por motivos específicos, mas essas restrições se implantaram por motivos diferentes; desse modo, uma situação emergente e a

53 AGCRJ, códice 42-3-17, folhas 4-5.

54 A Vida Fluminense. ano 1, n.3 (January 18, 1868), 40; ano 1, n.26 (jun. de 27, 1868) n/p. 
sua solução provisória se tornaram parte do funcionamento normal do estado no nível municipal.

Se o Toque de Aragão fazia sentido no contexto do início do Império e nas décadas seguintes, revogar esse regulamento também fazia todo sentido, uma vez que a vida comercial da cidade começou a se organizar em torno do entretenimento e da circulação nas ruas à noite, e uma vez que a mão de obra cativa foi substituída pelo trabalho livre. É possível dizer que a aplicação da lei contra a vadiagem entrou no lugar do toque de recolher como o dispositivo abrangente mais utilizado pela polícia para prender pessoas socioeconomicamente vulneráveis, simplesmente por estarem no espaço público da cidade, no lugar errado na hora errada. A vadiagem é uma contravenção mais adequada para trabalhadores não escravizados pegos no momento em que não estão trabalhando, numa cidade se industrializando que não parava mais - que não podia parar - com o pôr do sol.

Em outras palavras, o Toque de Aragão não deve ser visto simplesmente como uma antiguidade que desapareceu com o avanço tecnológico e a modernidade. O sino da igreja parou de tocar, mas a normalização da suspensão de direitos persistiu. ${ }^{55}$ Durante a Primeira República, quando o Toque de Aragão já tinha virado um assunto para os folcloristas nostálgicos, em vez de uma questão da polícia, o governo repetidamente invocava a razão do Estado para suspender direitos individuais e normas jurídicas durante períodos de resistência operária.

O estudo da noite apresenta desafios fascinantes para quem está interessado no estudo da sociedade urbana: como é que podemos estudar a ascensão da famosa vida noturna moderna carioca enquanto pensamos, ao mesmo tempo, na imposição de estados de sítio repetidas vezes no século XX que mirava a noite como cheia de possibilidades perigosas? Voltar ao início do Império e traçar a história das restrições à liberdade de movimento (como o Toque de Aragão), ao lado das mudanças tecnológicas, pode nos livrar da observação aparentemente óbvia de que a noite é mais perigosa que o dia, por motivos simplesmente biológicos e psicológicos. As reações políticas e jurídicas à noite são sintomas de uma dinâmica social e política. Até mesmo quando se tornou tecnologicamente possível para a cidade funcionar durante todas as 24 horas do dia sem parar, a noite ainda importava como um período distinto, um período que influenciava profundamente a relação entre o Estado no seu nível mais local e os seus cidadãos.

Recebido em 24/05/2013

Aprovado em 10/06/2013

55 O debate histórico e legal sobre os significados da lei suntuária no estado moderno é instrutivo aqui; GOODRICH, Peter. "Signs Taken for Wonders: Community, Identity, and a History of Sumptuary Law". Law and Social Inquiry, Malden, MA: Wiley-Blackwell/ American Bar Foundation, 23:3, 1998, p. 707-28. CHAZKEL, Amy. Laws of Chance: Brazil's Clandestine Lottery and the Making of Urban Public Life. Durham, NC: Duke University Press, 2011, p. 6-7. 